\title{
Forming property of Magnesium Alloy Sheet in Radial Pressure Deep Drawing
}

\author{
Xianchang Mao ${ }^{1, a}$, Haiyan Lin ${ }^{2, b}$ \\ ${ }^{1}$ School of Mechanical \& Electronic Engineering, Hezhou University, Hezhou, 542899, China \\ ${ }^{2}$ School of Economics and Management, Hezhou University, Hezhou 542899, China \\ aemail: mxchlhy@163.com, bemail: Ihyhezhou@163.com
}

\begin{abstract}
Keywords: Magnesium Alloy Sheet; Radial Pressure Deep Drawing; Mumerical Simulation; Forming Property
\end{abstract}

\begin{abstract}
The finite element model was established and the forming process of magnesium alloy sheet in radial pressure deep drawing was simulated by using the commercial FE software Dynaform. The influence of hydraulic pressure and die clearance on forming limit, wrinkle, wall thickness variations and distribution of magnesium alloy sheet were discussed respectively. The results indicate that magnesium alloy sheet showed poor deformation behaviors when the excessive hydraulic pressure (more than 25MPa) was adopted in radial pressure deep drawing. The obviously wall thickness thinning of workpieces always appeared at cylinder wall and punch corner, the maximum wall thinning was $0.103 \mathrm{~mm}$. Preferable wall thickness variations of AZ31B magnesium alloy can be obtained when the die clearance was increased moderately. The obtained maximum thickness thinning of AZ31B workpieces were $11.33 \%, 17.5 \%$ and $16 \%$ when the die clearance $\mathrm{C}$ were $0.66 \mathrm{~mm}, 0.6 \mathrm{~mm}$ and $0.56 \mathrm{~mm}$.
\end{abstract}

\section{Introduction}

As the most prospective metal material in the 21st century, magnesium alloy is trend to replace other common metal materials [1]. Especially Plastic forming of magnesium alloy parts, it has been popular with the attention in automotive an aircraft industry owing to their low density, high specific strength and excellent behaviors in shock absorption, corrosion resistance, etc [2]. Magnesium alloy warm forming is a common forming technology to improve the forming limit. Experimental study of magnesium alloy tubular parts in warm deep drawing was carried out by German scholars Droder [3]. The results show that excessive thinning in the dangerous section can be avoid at $200{ }^{\circ} \mathrm{C}$. But the development of warm forming is still limited because of it defects and deficiencies, such as equipment complex, Temperature control is difficult, magnesium alloy are easy to suffer from oxidation during warm forming [4]. Existing data suggest that magnesium alloys have poor formability at room temperature [5], and explore advanced forming method to avoid the shortage of the hot forming and improve the formability of magnesium alloy in the meantime is necessary [6]. Research shows that hydraulic forming especially radial pressure deep drawing can solve these questions. Therefore, the deformation behaviors and forming limit of AZ31B magnesium alloy sheet in radial pressure deep drawing will be investigated base on finite element software Dynaform.

\section{Numerical Simulation}

The working principle and mold structure of radial pressure deep drawing is shown in Fig. 1. Base on the principle and structural features of parts, Pro/ENGINEER was adopted to build surface modeling. Then mesh generation and surface repair were carried out by use of Dynaform. AZ31B magnesium alloy sheet was set as deformable object, and punch, die and blank holder were set as rigid body. Both deformable object and rigid body were meshed with four-node shell unit [7]. The forming mode was single action positive deep drawing, the whole load process was last $3 \times 10-3 \mathrm{~s}$. The whole undersurface of the AZ31B sheet was exerting an upward pressure on and the nodes in the round of AZ31B sheet were set radial pressure. The built finite element model is shown in 
Fig.2.Seen from above there include punch, blank holder, AZ31B sheet and die. The thickness of the sheet $t$ is $0.6 \mathrm{~mm}$ and the initial diameter $D$ is $70 \mathrm{~mm}$. The friction coefficient between sheet and die, punch and blank holder were respectively set as $0.02,0.2$ and 0.02 . The geometric size of the model as follows. Die diameter $d_{\mathrm{d}}$ is $30 \mathrm{~mm}$, die clearance $C$ are $0.66 \mathrm{~mm} 0.6 \mathrm{~mm}$ and $0.56 \mathrm{~mm}$, die profile radius $r_{\mathrm{d}}$ is $6 \mathrm{~mm}$, punch profile radius $r_{\mathrm{p}}$ is $5 \mathrm{~mm}$.

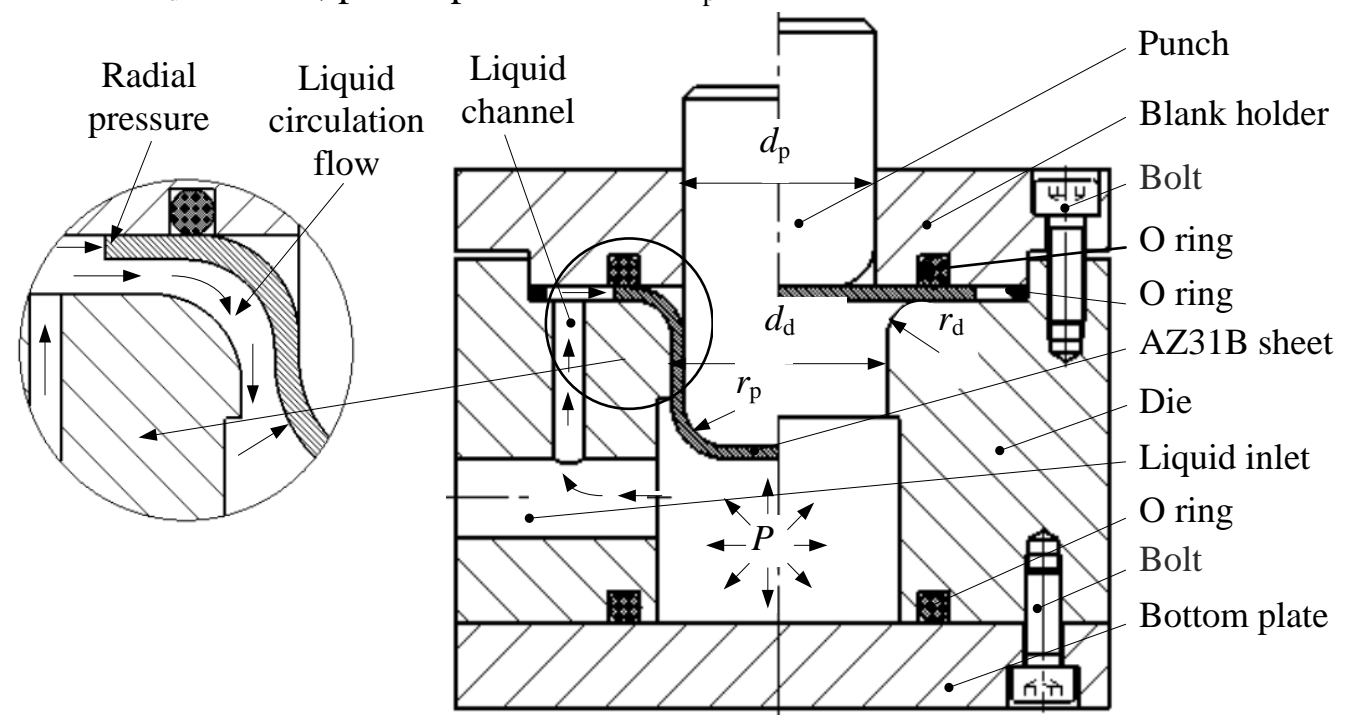

Fig. 1. Radial pressure deep drawing

After finishing the operation, the obtained FLD can be observed so as to analyze the fracture (red) and Serious thickening (blue) of AZ31B workpieces via the post processing function of Dynaform, as shown in Fig. 3. Owing to it is rotating member, AZ31B workpieces can be only choose a quarter to analyze in order to save operation time. During the numerical simulation process under different parameters, in order to insure the consistent data, wall thickness sampling sites of AZ31B workpieces should be chose as in Fig. 4.

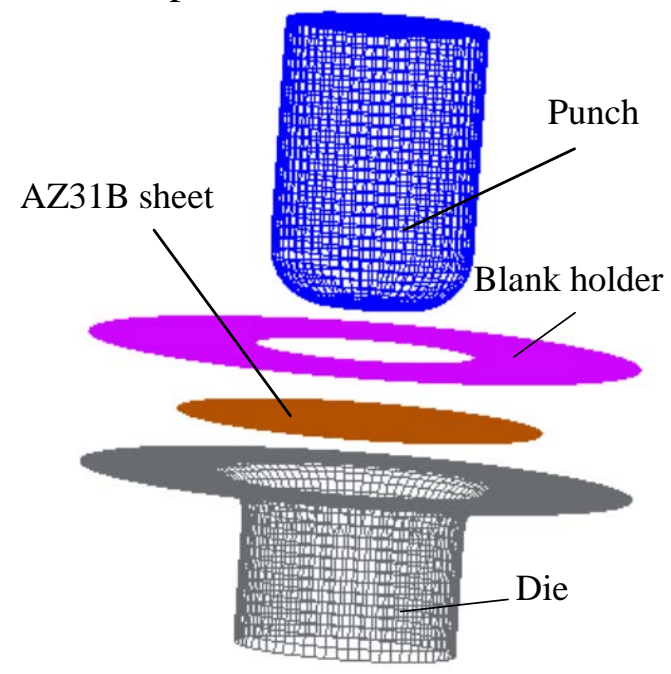

Fig.2. Finite element model

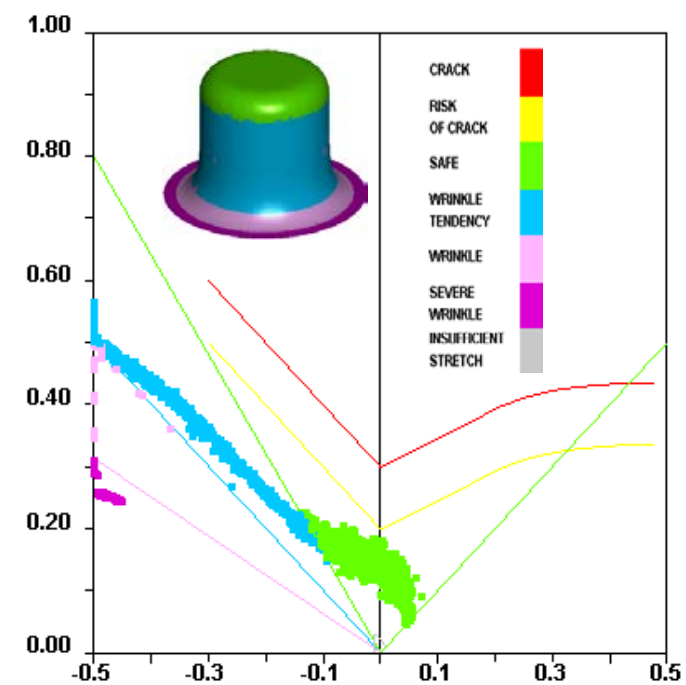

Fig.3. FLD of AZ31B sheet

\section{Results and Discussion}

Both theoretical study and numerical simulation were applied to investigate the influence of hydraulic pressure $P$ and die clearance $C$ on the forming property of AZ31B magnesium alloy sheet in radial pressure deep drawing. Then the forming limit and wall thickness distribution were analyzed detailedly.

Hydraulic Pressure. The influence of hydraulic pressure on forming property of AZ31B sheet was analyzed in this part and the geometric size of the model as follows. Die clearance $C$ are 0.66 $\mathrm{mm}$, die profile radius $r_{\mathrm{d}}$ is $6 \mathrm{~mm}$, punch profile radius $r_{\mathrm{p}}$ is $5 \mathrm{~mm}$, blank holder force $Q$ is $3392 \mathrm{~N}$. 
The obtained FLD and AZ31B workpiece under hydraulic pressure $P$ is $25 \mathrm{MPa}$ are shown in Fig. 5. Fig. 5 exhibits the sheet severe wrinkling in early stage, and the wrinkle cannot disappear even if at end of the forming, as shown in Fig. 5a and Fig. 5b.Therefore, this forming when $P$ is $25 \mathrm{MPa}$ is unsuccessful and it is insignificance to investigate the wall thickness distribution and forming limit.

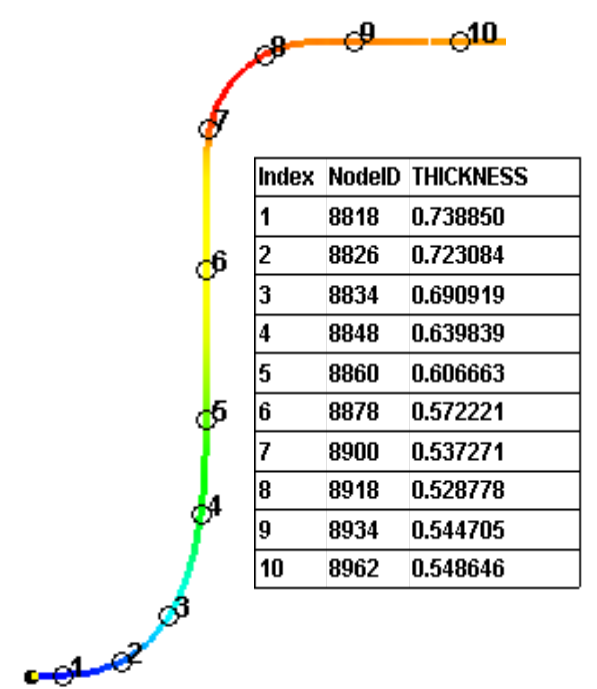

Fig.4. Wall thickness sampling site

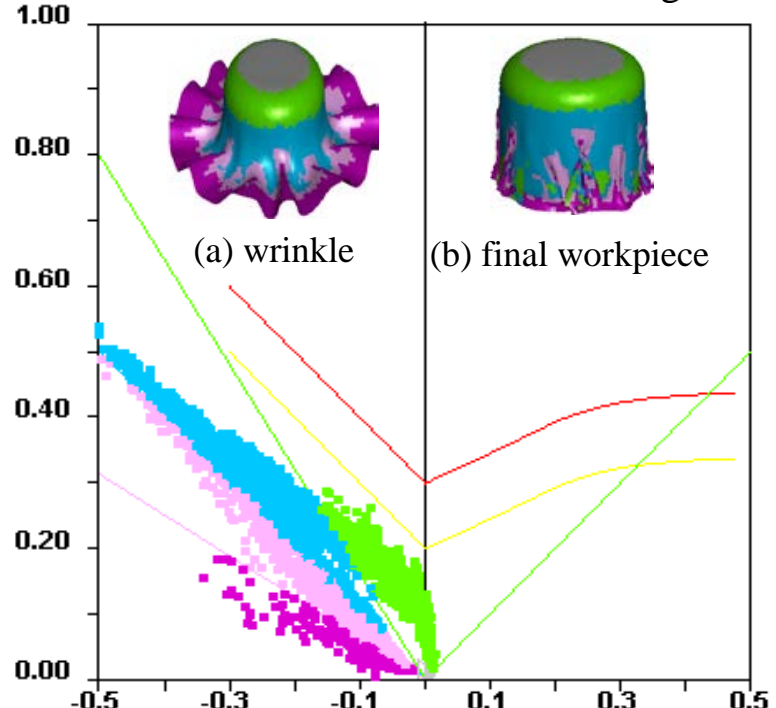

Fig.5. FLD of AZ31B sheet with $P=25 \mathrm{MPa}$

The FLD and wall thickness distribution of AZ31B workpiece when $P$ is 15 MPa are shown in Fig. 6a. It can be seen from Fig.6a that yellow but not red appears at punch fillet area. It means large amount of thinning appears at punch fillet area, compare with other areas of AZ31B workpiece. The results show that the minimum wall thickness value and maximum wall thickness of sampling sites are $0.518 \mathrm{~mm}$ and $0.714 \mathrm{~mm}$, as shown in Fig. 6b.Then the minimum wall thickness value and maximum wall thickness of AZ31B workpiece are $0.497 \mathrm{~mm}$ and $0.725 \mathrm{~mm}$, as shown in Fig. 6c.

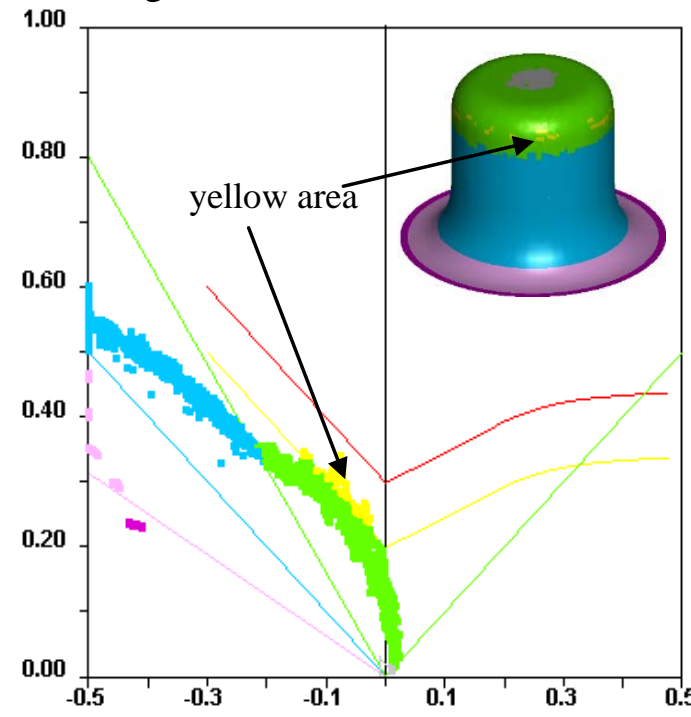

(a) FLD

\begin{tabular}{|l|l|l|}
\hline Index & NodeID & THICKNESS \\
\hline 1 & 8643 & 0.713936 \\
\hline 2 & 8653 & 0.686409 \\
\hline 3 & 8661 & 0.658586 \\
\hline 4 & 8671 & 0.629559 \\
\hline 5 & 8687 & 0.578995 \\
\hline 6 & 8705 & 0.536391 \\
\hline 7 & 8719 & 0.517950 \\
\hline 8 & 8735 & 0.530335 \\
\hline 9 & 8755 & 0.579679 \\
\hline 10 & 8777 & 0.588184 \\
\hline & & \\
\end{tabular}

(c) wall thickness colour

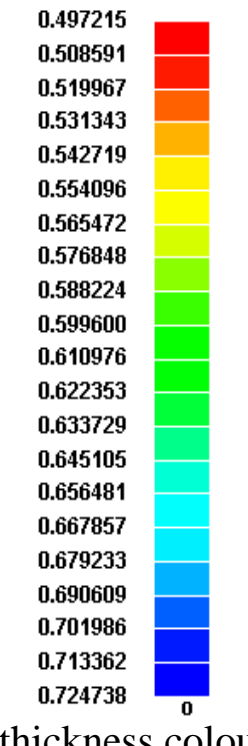

(b) wall thickness value

Fig.6. $P=15 \mathrm{MPa}$

The FLD and wall thickness distribution of AZ31B workpiece when $P$ is $5 \mathrm{MPa}$ are shown in Fig. 7a. Fig. 7a suggests that yellow but no red appears at punch fillet area and there is no crack appears at AZ31B workpiece. The research results show that the minimum wall thickness and maximum wall thickness of sampling sites are $0.518 \mathrm{~mm}$ and $0.713 \mathrm{~mm}$, as shown in Fig. 7b. Then the minimum wall thickness value and maximum wall thickness of AZ31B workpiece are 0.497 $\mathrm{mm}$ and $0.724 \mathrm{~mm}$, as shown in Fig. 7c.

Comparing the above three kinds of result, AZ31B sheet show a preferable forming property 
and the obtained wall thickness distribution is quite similar when $P$ is $15 \mathrm{MPa}$ and $5 \mathrm{MPa}$, but the deep drawing failure when $P$ is $25 \mathrm{MPa}$. Thus it can be seen that $P$ should less than $25 \mathrm{MPa}$ when die clearance $C$ are $0.66 \mathrm{~mm}$, die profile radius $r_{\mathrm{d}}$ is $6 \mathrm{~mm}$, punch profile radius $r_{\mathrm{p}}$ is $5 \mathrm{~mm}$ and blank holder force $Q$ is $3392 \mathrm{~N}$. Moreover, the minimum wall thickness value and maximum wall thickness value of sampling sites are not on behalf of the extremum of workpiece.

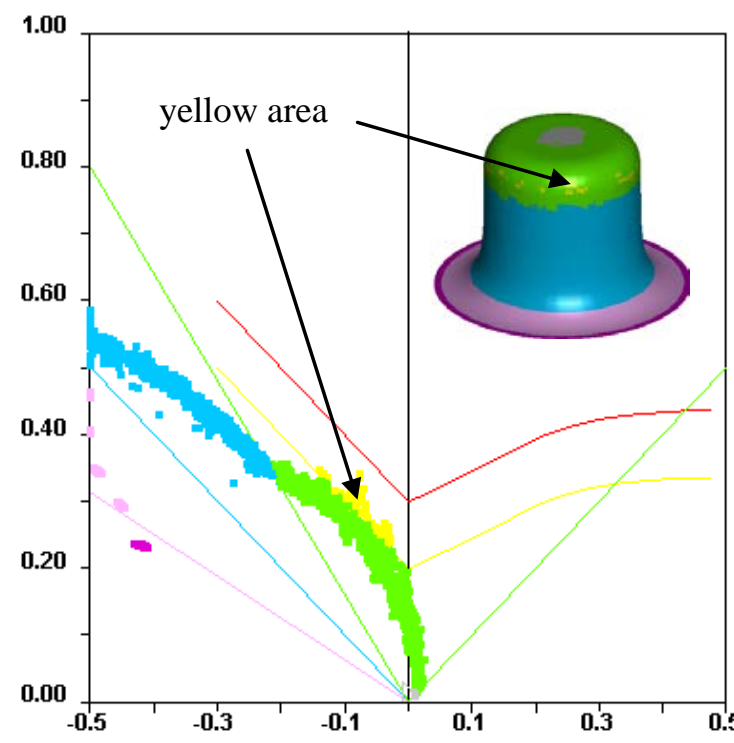

\begin{tabular}{|c|c|c|}
\hline Index & JodelD & IHICKNESS \\
\hline 1 & 3643 & 0.713439 \\
\hline 2 & 3653 & 0.684770 \\
\hline 3 & 3661 & 0.658353 \\
\hline 4 & 3675 & 0.619423 \\
\hline 5 & 3687 & 0.579881 \\
\hline 6 & 3701 & 0.542790 \\
\hline 7 & 3719 & 0.517904 \\
\hline 8 & 3735 & 0.530240 \\
\hline 9 & 3755 & 0.579558 \\
\hline 10 & 3777 & 0.588148 \\
\hline
\end{tabular}

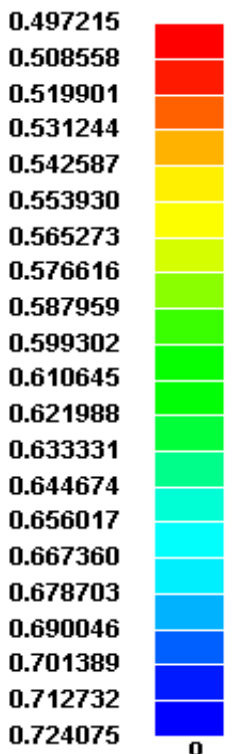

(a) FLD

(b) wall thickness value

(c) wall thickness colour

Fig.7. $P=5 \mathrm{MPa}$

Wall thickness distribution can be draw via collect the wall thickness values of Fig.6 and Fig.7, as shown in Fig.8. The above three figures show that excessive thickening appears at flange area (sit 1 and sit 2), moderate thickening appears at die fillet area, the thickness of cylinder wall and cylinder bottom almost no change. Then severe thinning was appears at the junction of cylinder wall and punch fillet area, the maximum thickness reduction is $0.103 \mathrm{~mm}$. Figure 8 suggest that compare with $P$ is $5 \mathrm{MPa}$, from sit 3 to sit 7 , the wall thickness has a slight change when $P$ is 15 $\mathrm{MPa}$, and the other wall thickness of AZ31B workpiece was almost no change.

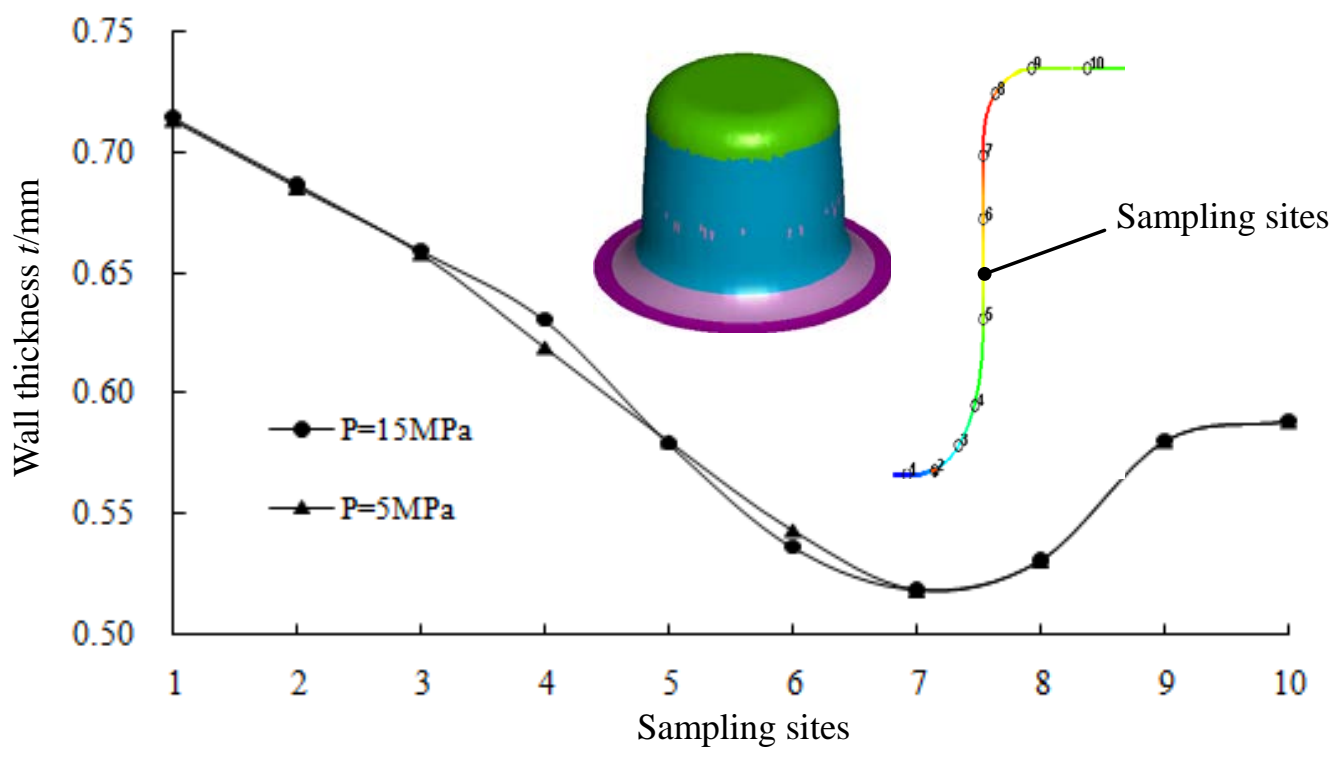

Fig.8. Wall thickness distribution of workpieces in $P$ is $5 \mathrm{MPa}$ and $15 \mathrm{MPa}$

Furthermore, the same value of minimum reduction ratio $17.17 \%$ can be obtained and the maximum thickening is $20.83 \%$ and $20.67 \%$ when $\mathrm{P}$ is $15 \mathrm{MPa}$ and $5 \mathrm{MPa}$. The existing data suggest that forming process is considered feasible when the wall thickness reduction less than $20 \%$ and the thickening is less than $5 \%$. So, Thinning is reasonable and thickening is unreasonable in this 
deep drawing.

Die Clearance. Die clearance is the clearance between punch and die which is expressed by unilateral space $C$. The influence of $C$ on forming property of AZ31B sheet was investigated in this part and the technological parameters as follows. Die profile radius $r_{\mathrm{d}}$ is $6 \mathrm{~mm}$, punch profile radius $r_{\mathrm{p}}$ is $5 \mathrm{~mm}$, blank holder force $Q$ is $3392 \mathrm{~N}$ and hydraulic pressure $P$ is $15 \mathrm{MPa}$.

Fig. 9a shows the obtained FLD of AZ31B workpiece when $C$ is $0.66 \mathrm{~mm}$. It can be seen from Fig. 9a that the thickness of cylinder wall did not change in hydraulic deep drawing process, there was no red or yellow appears at surface of workpiece and there was no significant wrinkling of the flange. So, it means that the above technological parameters can be adopted in magnesium alloy radial pressure deep drawing to obtain a preferable forming property. The results show that the minimum wall thickness value and maximum wall thickness value were $0.532 \mathrm{~mm}$ and $0.746 \mathrm{~mm}$.

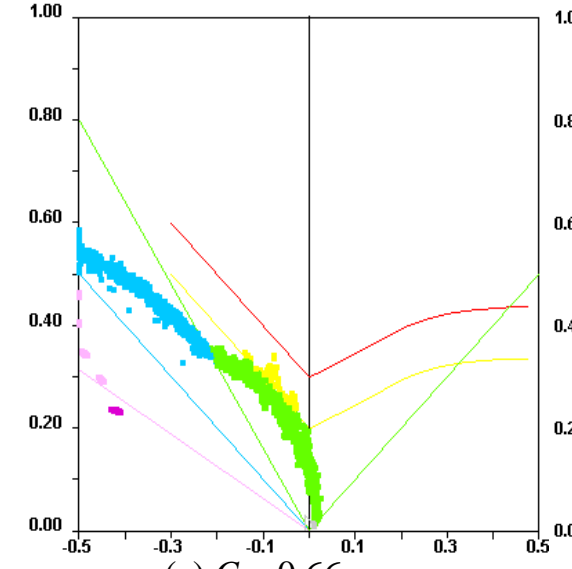

(a) $C=0.66 \mathrm{~mm}$

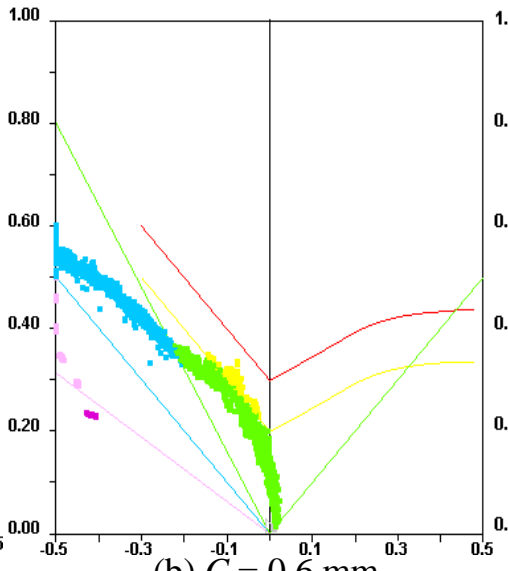

(b) $\stackrel{-0.1}{C}=0.6 \mathrm{~mm}$

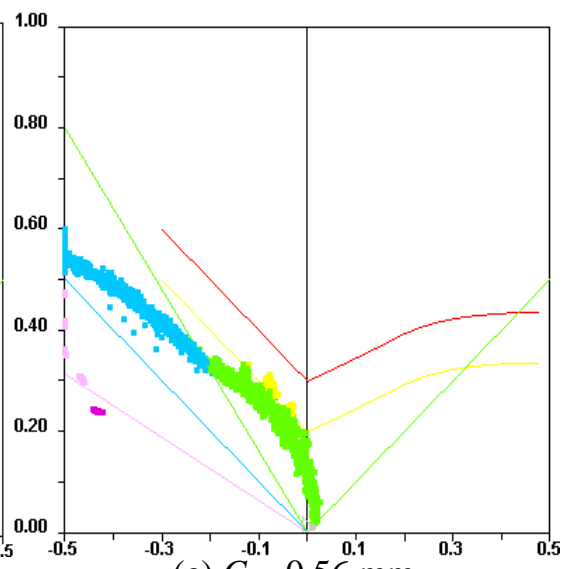

(c) $C^{-0.1}=0.56 \mathrm{~mm}$

Fig.9. FLD of AZ31B sheet in different die Clearance

The obtained FLD when $C$ is $0.6 \mathrm{~mm}$ and $0.56 \mathrm{~mm}$ are shown in Fig. 9b and Fig. 9c. It can be seen from Fig. 9b and Fig. 9c, yellow appears at junction of cylinder wall and punch fillet area which means large amount of thinning was appears at this area than other area of workpiece. But no red appears on workpiece so the workpiece has not yet occurred fracture. The results suggest that the minimum wall thickness value and maximum wall thickness value of magnesium alloy workpiece were $0.495 \mathrm{~mm}$ and $0.723 \mathrm{~mm}$ when $C$ is $0.6 \mathrm{~mm}$. Then the above two values were 0.504 $\mathrm{mm}$ and $0.728 \mathrm{~mm}$ when $C$ is $0.56 \mathrm{~mm}$.

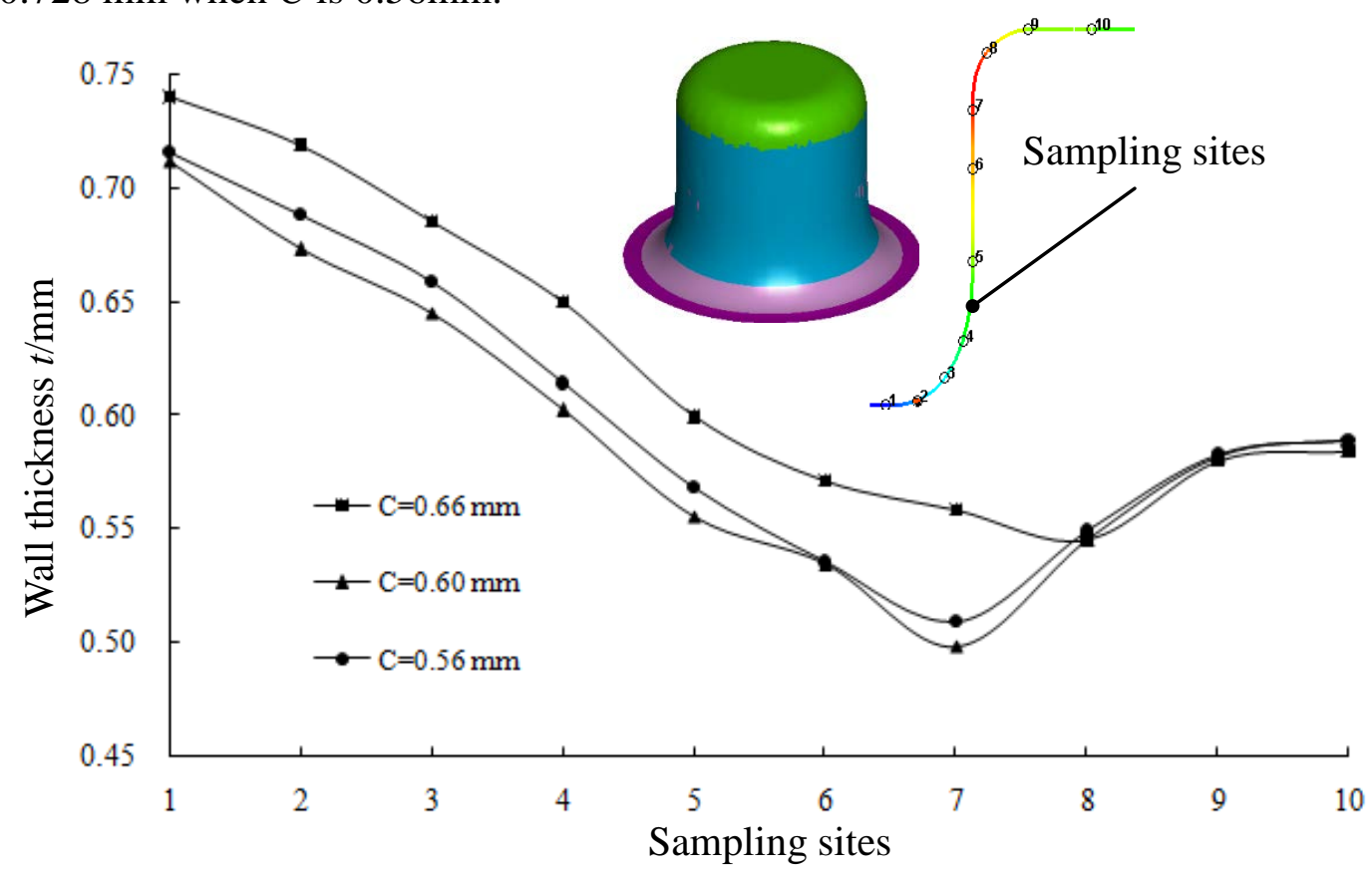

Fig.10. Wall thickness distribution of workpieces in different die Clearance 
Wall thickness distribution of AZ31B workpiece under three $C$ values is shown in Fig. 10. Fig. 10 exhibits larger thickening was appears at sit 1 and sit 2, slight thickening was appears at die fillet area, the thickness of cylinder wall and cylinder bottom almost no change, the severe thinning was appears at the junction of cylinder wall and punch fillet area. The results show that wall thickness thinning can be retard and forming property of AZ31B sheet will be improved if appropriate increase $C$. Furthermore, the obtained data display that the minimum thinning ratio is $11.33 \%$, $17.5 \%$ and $16 \%$ and the maximum thickening ratio is $24.33 \%, 20.5 \%$ and $21.33 \%$ when $\mathrm{C}$ is 0.66 $\mathrm{mm}, 0.6 \mathrm{~mm}$ and $0.56 \mathrm{~mm}$. Thus it can be seen wall thickness thinning is reasonable and the thickening is still below standard.

\section{Conclusions}

Magnesium alloy shows poor deformation behaviors in radial pressure deep drawing when hydraulic pressure is more than 25MPa. AZ31B sheets show preferable forming property and the obtained wall thickness distribution is quite similar when $P$ is $15 \mathrm{MPa}$ and $5 \mathrm{MPa}$. Large thickening appear at flange area, moderate thickening was appear at die fillet area, the thickness of cylinder wall and cylinder bottom almost no change. Then severe thinning was appears at the junction of cylinder wall and punch fillet area, the maximum thickness reduction is $0.103 \mathrm{~mm}$. The same minimum reduction ratio value $17.17 \%$ was obtained and the maximum thickening was $20.83 \%$ and $20.67 \%$ when $P$ is $15 \mathrm{MPa}$ and $5 \mathrm{MPa}$. Wall thickness thinning can be retard and forming property of AZ31B sheet can be improved if appropriate increases $C$. The minimum thinning ratio is $11.33 \%$, $17.5 \%$ and $16 \%$ and the maximum thickening ratio is $24.33 \%, 20.5 \%$ and $21.33 \%$ when $\mathrm{C}$ is 0.66 $\mathrm{mm}, 0.6 \mathrm{~mm}$ and $0.56 \mathrm{~mm}$.

\section{Acknowledgement}

In this paper, the research was sponsored by the Young and Middle-aged Teacher Basic Ability Promotion Program Foundation of Guangxi Province (Project No. KY2016YB456), College Student Innovative Entrepreneurial Training Program Foundation of Guangxi Province (Project No. 201411838005), Science Foundation of Hezhou University (Project No. 2014YBZK01) and College Student Research Training Program of Hezhou University(Project No. 2014DXSKJ07).

\section{References}

[1] LI Yida, LIANG Minjie, LIAO Haihong. Research Progress of Advanced Magnesium Alloys and Its Application in Auto Industry [J]. Hot Working Technology, 2013, 42(10): 12-16.

[2] El-morsy Abdel-wahab, MANABE Ken-ichi. Finite element analysis of magnesium AZ31 alloy sheet in warm deep-drawing process considering heat transfer effect[J]. Materials Letters, 2006. 60(15): 1866-1870

[3] K. Droder. Analysis on forming of thin magnesium sheets [J]. Ph.D. Dissertation, IFUM, University of Hanover, 1999, 10(1): 92-98.

[4] MAO Xian-chang. Experiments of AZ31B magnesium alloy sheets in radial pressure deep drawing [J]. Journal of Plasticity Engineering, 2012, 19(4): 43-48.

[5] YANG L F, MORI K I. Deformation behaviors of magnesium alloy AZ31 sheet in cold deep drawing $[\mathrm{J}]$.

[6] HUSEYIN S H, MEVLUT T, MURAT D. Enhancing formability in hydromechanical deep drawing process adding a shallow drawbead to the blank holder [J]. Journal of Materials Processing Technology, 2014, 214(5): 1638-1646.

[7] Xianchang MAO, Haiyan LIN. Thickness of magnesium alloy cylindrical cup in pressure-lubricating deep drawing [J]. Applied Mechanics and Materials, 2012, 189: 147-151. 